\title{
Differential Requirements for Semaphorin 3F and Slit-1 in Axonal Targeting, Fasciculation, and Segregation of Olfactory Sensory Neuron Projections
}

\author{
Jean-François Cloutier, ${ }^{1,2 \star}$ Amar Sahay, ${ }^{1 \star}$ Ernie C. Chang, ${ }^{4}$ Marc Tessier-Lavigne, ${ }^{3}$ Catherine Dulac, ${ }^{4}$ Alex L. Kolodkin, ${ }^{1}$ \\ and David D. Ginty ${ }^{1,2}$ \\ ${ }^{1}$ Department of Neuroscience, ${ }^{2}$ Howard Hughes Medical Institute, The Johns Hopkins University School of Medicine, Baltimore, Maryland 21205, \\ ${ }^{3}$ Department of Biological Sciences, Howard Hughes Medical Institute, Stanford University, Stanford, California 94305, and ${ }^{4}$ Department of Molecular and \\ Cellular Biology, Howard Hughes Medical Institute, Harvard University, Cambridge, Massachusetts 02138
}

The formation of precise stereotypic connections in sensory systems is critical for defining accurate internal representations of the external world; however, the molecular mechanisms underlying the formation of sensory maps are poorly understood. Here, we examine the roles of two structurally unrelated repulsive guidance cues, semaphorin 3F (Sema3F) and Slit-1, in olfactory sensory axon fasciculation, targeting, and segregation. Using sema $3 \mathrm{~F}^{-1-}$ mice, we show that Sema3F is critical for vomeronasal sensory neuron axonal fasciculation and for segregation of these sensory afferents from the main olfactory system; however, Sema3F plays only a minor role in targeting of apical vomeronasal neuron axons to the anterior accessory olfactory bulb (AOB). In addition, we show that Sema3F is required for lamina-specific targeting of olfactory sensory axons within the main olfactory system. In contrast to Sema3F, Slit-1 is dispensable for fasciculation of basal vomeronasal neuron axons but is critical for targeting these axons to the posterior AOB. These results reveal discrete and complementary roles for secreted semaphorins and slits in axonal targeting, fasciculation, and segregation of olfactory sensory neuron projections.

Key words: semaphorins; slits; olfactory; vomeronasal; targeting; fasciculation

\section{Introduction}

The formation of precise connections between sensory neurons in the periphery and their targets in the CNS is critical for proper perception of the environment. Two anatomically distinct chemosensory systems are involved in olfactory perception in most terrestrial vertebrates: the main and accessory olfactory systems (Halpern, 1987; Buck, 2000; Mombaerts, 2001; Dulac and Torello, 2003). In both systems, primary sensory neurons located in the periphery

\footnotetext{
Received July 12, 2004; revised Sept. 1, 2004; accepted Sept. 2, 2004

This work was supported by the National Institutes of Health (NIH)-National Institute of Mental Health Grant R01MH59199 (D.D.G. and A.L.K.), NIH-National Institute on Deafness and Other Communication Disorders Grant R01DC003903-06 (C.D.), the McKnight Endowment Fund for Neuroscience (A.L.K.), and the Canadian Institutes of Health Research and NARSAD (J.-F.C.). D.D.G. and C.D. are investigators of the Howard Hughes Medical Institute. We thank members of the Ginty and Kolodkin laboratories for helpful discussion and technical advice. We are grateful to Frank Margolis for anti-OMP serum, David Ornitz for mouse slit CDNA clones, and Alain Chédotal for rat Robo CDNA clones. We also thank Jolanta Dubauskaite for pronuclear injections of the EC2-ITL construct.

*J.-F.C. and A.S. contributed equally to this work.

Correspondence should be addressed to either of the following: David D. Ginty, Department of Neuroscience, Howard Hughes Medical Institute, The Johns Hopkins University School of Medicine, 725 North Wolfe Street, Baltimore, MD 21205, E-mail: dginty@jhmi.edu; or Alex L. Kolodkin, Department of Neuroscience, The Johns Hopkins University School of Medicine, 725 North Wolfe Street, Baltimore, MD 21205, E-mail: kolodkin@jhmi.edu.

J.-F. Cloutier's present address: Montreal Neurological Institute, McGill University, Department of Neurology and Neurosurgery, 3801 University, Montréal, Québec, Canada H3A 2B4.

A. Sahay's present address: Columbia University, College of Physicians and Surgeons, Center for Neurobiology and Behavior, 1051 Riverside Drive, Box 87, PI Annex, Room 767B, New York, NY 10032.

M. Tessier-Lavigne's present address: Genentech Inc., 1 DNA Way, South San Francisco, CA 94080.

D01:10.1523/JNEUROSCI.2786-04.2004

Copyright $\odot 2004$ Society for Neuroscience $\quad 0270-6474 / 04 / 249087-10 \$ 15.00 / 0$
}

form zone-to-zone stereotypic connections with second-order neurons located in target fields within the CNS.

Zonal targeting in the accessory olfactory system involves two spatially distinct populations of sensory neurons within the vomeronasal organ (VNO), which extend axons that innervate either the anterior or posterior regions of the accessory olfactory bulb (AOB) (Halpern et al., 1995, 1998; Jia and Halpern, 1996). Vomeronasal sensory neurons express putative pheromone receptors (VRs), which belong to the large family of seventransmembrane G-protein-coupled receptors (Dulac and Axel, 1995; Herrada and Dulac, 1997; Matsunami and Buck, 1997; Ryba and Tirindelli, 1997; Pantages and Dulac, 2000; Rodriguez et al., 2002). Sensory neurons located in the apical portion of the VNO express either V1R or V3R receptors, which signal through the $\mathrm{G} \alpha_{\mathrm{i} 2}$ subunit of G-proteins, and their axons innervate glomeruli restricted to the anterior region of the $\mathrm{AOB}$. In contrast, vomeronasal neurons of the basal region of the VNO express receptors of the V2R subfamily, which signal through $\mathrm{G} \alpha_{\mathrm{o}}$ and project their axons to glomeruli located in the posterior half of the AOB (Jia and Halpern, 1996). The molecular mechanisms that orchestrate the segregation of vomeronasal projections to the anterior and posterior halves of the $\mathrm{AOB}$ are just beginning to be understood.

Emerging evidence points to critical roles of several families of axon guidance cues for the development of the accessory olfactory system. One member of the Ephrin (Eph) family, Ephrin A5, is required for targeting of V1R-expressing vomeronasal axons to the 
anterior $\mathrm{AOB}$, presumably through interactions with the Eph receptor EphA6 (Knoll et al., 2001). The targeting of apical vomeronasal axons to the anterior AOB is also dependent on repulsive forces from the posterior $\mathrm{AOB}$ that signal, at least in part, through neuropilin-2 (Npn-2) (Cloutier et al., 2002). Indeed, analysis of $n p n-2$ mutant mice reveals that Npn-2 is required for targeting of apical vomeronasal axons to the anterior AOB (Cloutier et al., 2002; Walz et al., 2002). Furthermore, Npn-2 is required for fasciculation of the vomeronasal nerve and also for separation of main and accessory olfactory projections during development (Cloutier et al., 2002; Walz et al., 2002). Although the expression patterns of the Npn-2 ligands Sema3F, Sema3B, and Sema3C in the accessory olfactory system suggest that they may signal through Npn-2 to direct the development of olfactory projections, their precise roles in fasciculation, segregation, and targeting of vomeronasal axons remain to be determined.

The guidance cues that direct segregation of basal vomeronasal axons to the posterior AOB have yet to be clearly defined. The Slit and Robo families of axon guidance molecules have been proposed to function as cues for basal vomeronasal axons (Knoll et al., 2003). Indeed, vomeronasal neurons are repelled by slit proteins in vitro, and the Slit receptor Robo- 2 is expressed in vomeronasal neurons located in the basal region of the VNO (Marillat et al., 2002; Knoll et al., 2003).

To evaluate the roles played by secreted semaphorin and slit repellents in the development of the accessory olfactory system, we have analyzed vomeronasal projections in mice lacking the Npn-2 ligand, Sema3F, or the Robo-2 ligand, Slit-1. Our results show that Sema3F-Npn-2 signaling is essential for fasciculation of the vomeronasal nerve as it courses past the main olfactory bulb (MOB) but is largely dispensable for targeting of apical vomeronasal axons to the anterior AOB. Moreover, Sema3F is required for the segregation of sensory neuron projections within the main and accessory olfactory systems and for accurate laminar targeting of main olfactory sensory neuron axons. In contrast to Sema3F, Slit-1 is not required for fasciculation of the vomeronasal nerve but is critical for targeting of basal vomeronasal sensory neuron axons to the posterior AOB. Together, these results show that two families of secreted repellents play complementary roles in the development of primary sensory projections in the accessory olfactory system.

\section{Materials and Methods}

Generation of EC2 tau-LacZ mouse line. A C57BL/6j mouse BAC array (RPCI-23, segment 2) was screened for EC2-containing bacterial artifi-
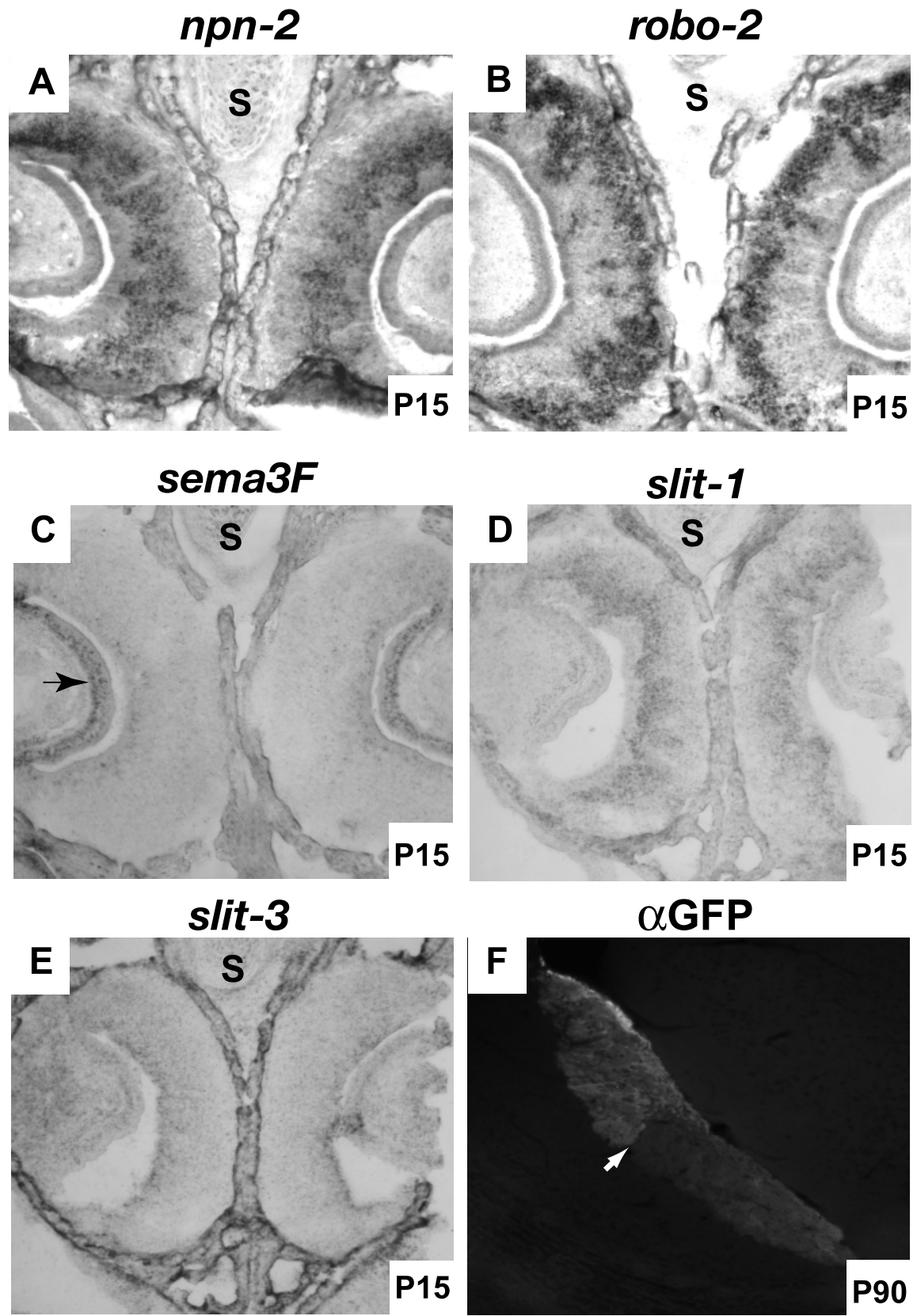

Figure 1. Expression of secreted semaphorins, slits, and their receptors in the VNO. $A-E$, In situ hybridization of VNO coronal sections at $\mathrm{P} 15$ with CRNA probes specific for $n p n-2(A)$, robo-2 $(B)$, sema3 $F(C)$, slit- $1(D)$, and slit-3 $(E)$. Expression of $n p n-2$ is restricted to the apical region of the VNO $(A)$, whereas robo-2 expression is detected in the basal region of the VNO $(B)$. Apical and basal VNO neurons project their axons to the anterior and posterior halves of the $A 0 B$, respectively. The secreted semaphorin sema3F is expressed mainly in the nonsensory epithelium of the VNO (arrow) and in a subpopulation of apical vomeronasal neurons (C). Expression of high levels of slit-1 and low levels of slit-3 is observed in apical vomeronasal neurons. $F$, slit-1expressing vomeronasal sensory neuron axons are targeted to the anterior AOB. Shown is a parasagittal section of the accessory olfactory bulb from a slit- $1^{+/-}$mouse stained with anti-GFP. The specific genetic targeting strategy used to generate this mouse slit-1 allele results in expression of GFP under the control of the slit-1 promoter. GFP-expressing vomeronasal sensory neurons extend axons that project to the anterior half of the $A O B$, commensurate with the expression pattern of slit- 1 within the VNO.

cial chromosomes (BACs). Positive BACs were extensively analyzed by PCR, DNA sequencing, and restriction digests to assert the presence of the EC2 gene. Two EC2 gene fragments were amplified from BAC449 D10 and modified by recombinant PCR with Pfu (Stratagene, La Jolla, CA) for homologous recombination within the EC2 BAC. A 5' arm was generated by amplification with oligonucleotides EC2-5'f (5'-GGC GCG CCT CGA GTC GAC GGC AGC ATT GCA AGA CTT CTT TCA TTA CC-3') and EC2-5'r (5'-GGC GCG CCC ATT CAG GAA TTT GAT TTT TCT TTG ATC TTT TGG-3') to generate a 1 kb DNA fragment with 
AscI, XhoI, and SalI sites at the 5' end and AscI site at the $3^{\prime}$ end of the EC2 genomic sequence. A $3^{\prime}$ arm was generated by amplification using oligonucleotides EC2-3' $f$ ( $5^{\prime}$-GGC GCG CCA ATA ATT CAG GAA TTA TGT AAA ATG-3') and EC2-3'r (5'-ACG CGT CTC GAG TCG ACA GGA CCT CAA TTA GAA CTG CAC ACA GAG G-3') to generate a $1.2 \mathrm{~kb}$ DNA fragment with an AscI site at the $5^{\prime}$ end and SalI and XhoI sites at the $3^{\prime}$ end. Both DNA fragments were subcloned by blunt Topo cloning into pCR Blunt4 Topo (Invitrogen, Gaithersburg, MD). The 1 kb EC2 5' DNA fragment was isolated after AscI digestion and subcloned into the $3^{\prime}$ arm digested by MluI and AscI, destroying the MluI site and the distal AscI site of the $5^{\prime}$ arm, creating the plasmid EC2 arms. Internal ribosomal entry site tau-lacZ subcloned as an AscI fragment into AscI digested, SAP (synapse-associated protein) dephosphorylated (Roche, Hertfordshire, UK) EC2 arms created the EC2-ITL (IRES tau-lacZ) cassette. The EC2ITL cassette was subcloned as a SalI fragment into pSV-recA to create pSV-EC2-ITL, which was subsequently used to modify BAC 449 D10 as described previously (Yang et al., 1997). Pronuclear injections of BAC EC2-ITL were used to generate three independent lines. Founders were crossed to $\mathrm{C} 57$ mice, and $\mathrm{F} 1$ animals were analyzed for lacZ expression by whole-mount 5-bromo-4-chloro-3-indolyl- $\beta$-D-galactopyranoside (Xgal) staining as described previously (Mombaerts et al., 1996).

In situ hybridization. Fresh frozen brains were cryosectioned at $20 \mu \mathrm{m}$, and sections were allowed to dry for $2 \mathrm{hr}$. After fixation (PBS containing $4 \%$ paraformaldehyde) for $20 \mathrm{~min}$, sections were washed three times in $\mathrm{PBS}$, rinsed once in DEPC water, and then acetylated for $10 \mathrm{~min}$. Sections were then washed twice in PBS and once in $2 \times$ SSC. Prehybridization was performed overnight in Dako (Carpinteria, CA) hybridization solution (Dako mRNA in situ hybridization solution code no. S3304). Hybridization was performed at $60^{\circ} \mathrm{C}$ overnight, and antisense and sense probes were used at a final concentration of $1 \mu \mathrm{g} / \mathrm{ml}$. After hybridization, sections were washed briefly in $10 \mathrm{~mm}$ Tris- $\mathrm{HCl}, \mathrm{pH}$ 7.5, $500 \mathrm{~mm} \mathrm{NaCl}$, and $1 \mathrm{~mm}$ EDTA at $60^{\circ} \mathrm{C}$ and RNase treated for $2 \mathrm{hr}$. Sections were then washed in high-stringency wash buffer $(0.2 \times$ SSC, $50 \%$ formamide $)$ for $30 \mathrm{~min}$ at $60^{\circ} \mathrm{C}$ followed by a $5 \mathrm{~min}$ wash in $0.2 \times \mathrm{SSC}$ at room temperature. For immunological detection, sections were processed as described previously (Cloutier et al., 2002; Sahay et al., 2003). Anti-digoxigeninalkaline phosphatase (AP)-Fab was used at a dilution of 1:3500 in blocking buffer. Sections were mounted using Moviol (Sahay et al., 2003).

Immunohistochemical procedures. Mice were perfused and olfactory bulbs were cryopreserved and sectioned as described previously (Cloutier et al., 2002). Cryosections $(25 \mu \mathrm{m})$ were washed, blocked, and processed for immunohistochemical detection as described previously (Cloutier et al., 2002). Primary antibodies and/or Fluorescein-Erythrina-Crystagalli lectin were applied at the following dilutions: anti-GTP binding protein $\mathrm{G}_{\mathrm{o} \alpha}(1 \mu \mathrm{g} / \mathrm{ml}$; Medical and Biological Laboratories, Woburn, MA), anti- $\mathrm{G}_{\mathrm{i} 2-\infty}(1: 300$; Wako Pure Chemical Industries, Osaka, Japan), anti-green fluorescent protein (GFP) (1:3000; Molecular Probes, Eugene, OR), anti-olfactory marker protein (OMP) (1:3000; kindly provided by Dr. Frank Margolis, University of Maryland School of Medicine), and EC lectin (1:500; Vector Laboratories, Burlingame, CA).

$X$-gal staining. Whole-mount X-gal staining was performed as described previously (Mombaerts et al., 1996).

\section{Results}

Expression of the secreted semaphorin receptor Npn-2 is restricted to vomeronasal neurons located in the apical region of the VNO (Fig. 1A) (Cloutier et al., 2002). In vivo analyses of vomeronasal projections in $n p n-2^{-/-}$mice indicate that Npn-2 is critical for fasciculation of the vomeronasal nerve, for targeting of apical vomeronasal sensory neuron axons to the anterior AOB, and for segregation of accessory and main olfactory sensory neuron projections (Cloutier et al., 2002; Walz et al., 2002). Although the exact mechanism by which Npn-2 mediates these effects remains unclear, several Npn-2 ligands, including Sema3F, are expressed in the main and accessory olfactory systems (Giger et al., 1998; Cloutier et al., 2002; Walz et al., 2002). In addition to its expression in cells that flank the path of vomeronasal sensory neuron axons, sema3F is also expressed in the VNO (Fig. 1C)
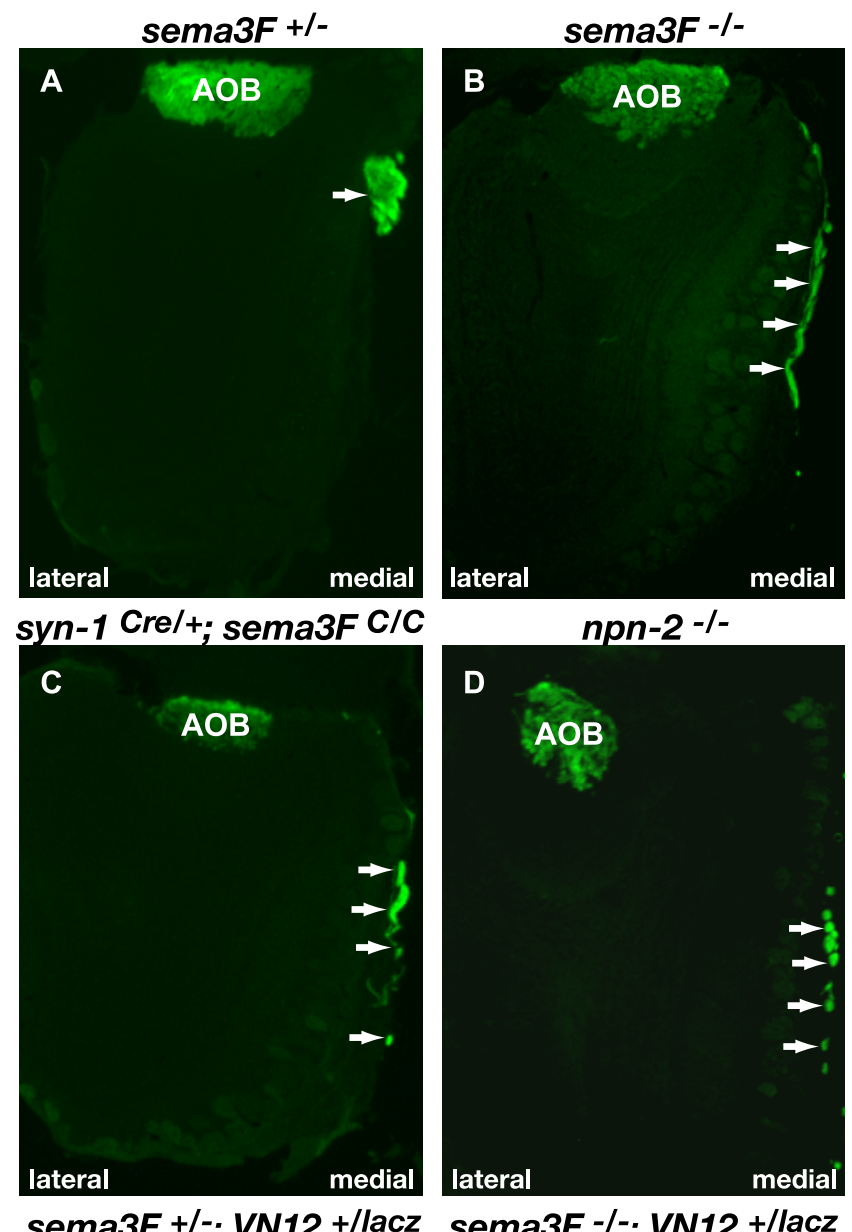

sema3F +/-; VN12 +/lacz
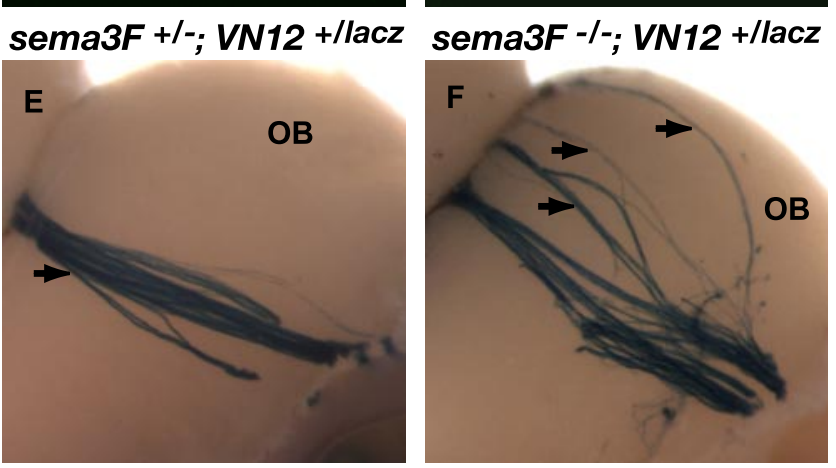

Figure 2. The vomeronasal nerve is defasciculated in sema3 $F^{-1-}$ mice. $A-D$, Coronal sections of olfactory bulbs at similar rostral-caudal axial levels from 6 - to 9 -week-old sema $3 F^{+/-}$

$(A)$, sema3 $\mathrm{F}^{-/-}(B)$, syn- $7^{\text {(rel+ }} ;$ sema3 $\mathrm{F}^{\mathrm{C} / \mathrm{C}}(C)$, and $n p n-2^{-1-}(D)$ mice stained with EC lectin. The large bundle of vomeronasal fibers, constituting the vomeronasal nerve, observed in sema $3 \mathrm{~F}^{+/-}$mice is defasciculated into several smaller bundles distributed along the dorsalventral axis of the medial region of the olfactory bulb in $\operatorname{sema3}^{-1-}(B)$, syn- $^{\text {(ree/ }}{ }^{+} ;$sema $3 \mathrm{~F}^{/ / C}$ $(C)$, and $n p n-2^{-/-}(D)$ mice. Arrows indicate vomeronasal nerve. For sema3F, $n=2(+/+)$, $n=3(+/-), n=3(-/-) ;$ syn- $7^{\mathrm{Cre} /+}$ sema3F, $n=3(+/ C), n=3(\mathrm{C} / \mathrm{C}) ; n p n-2, n=1$ $(+/-), n=1(-/-)$.C, Conditional. E, $F$, Whole-mount high-magnification view of primary vomeronasal projections observed using X-gal staining in 9-week-old sema3F ${ }^{+/-} ; V_{N 12}{ }^{+/ l a c Z}$ $(E)$ and sema3F $F^{-/-} ; V N 12^{+/ l a c Z}(F) . E$, Arrowhead points to vomeronasal fibers growing along the medial surface of the MOB toward the $A O B$. $F$, Arrows show defasciculated individual vomeronasal nerve coursing over the surface of the MOB. For sema3F; VN12 ${ }^{+ \text {Ilac }}, n=5(+/-)$, $n=5(-/-)$.

(Giger et al., 1998). Throughout development, sema3F expression in the VNO is highest in the nonsensory portion of the VNO; however, low levels of Sema3F mRNA are also observed in a subset of sensory neurons located in the apical VNO (Fig. 1C) (data not shown). The expression of sema3F throughout the ac- 
cessory olfactory system and its ability to repel axons of vomeronasal neurons suggest that Sema3F mediates Npn-2dependent fasciculation of the vomeronasal nerve and targeting of apical vomeronasal sensory neuron axons (Cloutier et al., 2002).

The vomeronasal nerve is defasciculated and vomeronasal sensory neuron axons ectopically innervate the main olfactory bulb in sema $3 F^{-/-}$mice

The observations that sema3F is highly expressed in cells of the medial MOB and that Sema3F is a potent vomeronasal sensory neuron axonal chemorepellent in vitro (Cloutier et al., 2002) raise the possibility that Sema3F-Npn-2 signaling mediates fasciculation of the vomeronasal nerve. We therefore examined the integrity of vomeronasal projections in mice harboring a null mutation in sema3F (Sahay et al., 2003). Coronal sections of main olfactory bulbs from 6- to 9-week-old sema $3 F^{+/-}$or sema $3 F^{-/-}$mice were stained with Erythrina Cristagalli (EC) lectin to visualize all vomeronasal sensory neuron axons projecting to the $\mathrm{AOB}$ (Tanaka et al., 1999). In sema3 $F^{+/-}$mice, these axons are tightly fasciculated and form a large bundle, the vomeronasal nerve, which courses along the medial surface of the MOB (Fig. $2 A$ ). In contrast, many smaller axon bundles are observed along the dorsoventral axis of the MOB in sema $3 F^{-/-}$mice (Fig. $2 B$ ), reminiscent of what is observed in $n p n-2^{-/-}$mice (Fig. 2D) (Cloutier et al., 2002).

To better define the role of Sema3F in vomeronasal projections, we generated sema $3 F^{-1-}$ mice that express tau-lac $Z$ in a specific subpopulation of apical vomeronasal neurons. The expression of tau-lac $Z$ in neurons that also express the V1R VN12 receptor allowed us to visualize projections from this specific population of apical vomeronasal sensory neurons (Belluscio et al., 1999). Whole-mount X-gal staining of the olfactory bulb reveals VN12-expressing vomeronasal axons projecting along the medial surface of the MOB in the direction of the AOB. Although these axons are tightly bundled in $\mathrm{sema} \mathrm{F}^{+/-} ; \mathrm{VN} 12^{+/ l a c Z}$ mice, they are dramatically defasciculated in $\mathrm{sema} \mathrm{F}^{-/-} ; \mathrm{VN} 12^{+/ l a c Z}$ mice (Fig. $2 E, F$ ). Interestingly, despite the severe defasciculation of the vomeronasal nerve, most of the $\mathrm{VNO}$ axons reach their target region in the $\mathrm{AOB}$ (see Fig. $4 I, J$ ); however, a small number of $\mathrm{VN} 12^{+/ l a c Z}$ axons ectopically terminate in the MOB (see Fig. 5) (data not shown). To determine whether these ectopic fibers enter and innervate the glomerular layer of the MOB, coronal sections of the MOB at rostral levels were stained with EC lectin to visualize ectopically projecting vomeronasal sensory neuron axons. In sema3 $F^{-1-}$ mice, these ectopically projecting axons enter the MOB and terminate within the glomerular layer (Fig. 3B). Staining of coronal olfactory bulb sections with EC lectin and anti-OMP to visualize all primary olfactory axons, and with Hoechst to visualize periglomerular cells, further reveals that these ectopic vomeronasal sensory neuron axons indeed inner-
sema3F -/-

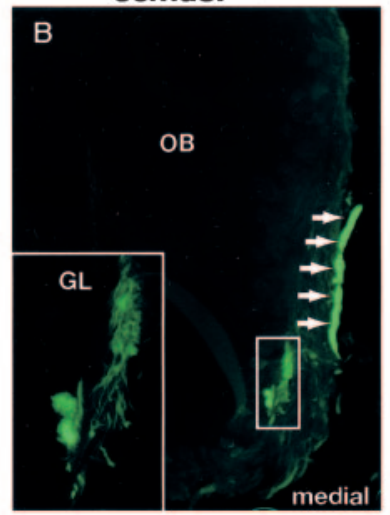

sema3F -/-

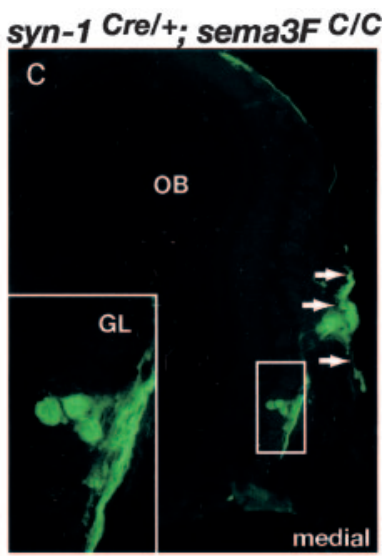

Figure 3. Defasciculated vomeronasal sensory axons ectopically innervate the main olfactory bulb in sema3F ${ }^{-1-}$ mice. $A-C$

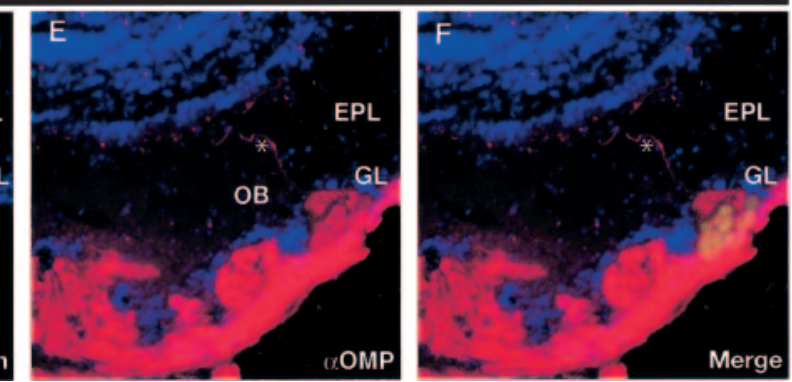

EP

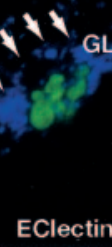

Coronal sections of olfactory bulbs at similar rostral-caudal axial levels from 6- to 9-week-old sema3 $F^{+/-}(A)$, sema3 $F^{-1-}(B)$, syn-1 $1^{\mathrm{Cre} /+}$ sema3F $\mathrm{F}^{\mathrm{C} / \mathrm{C}}(C)$ mice stained with $\mathrm{EC}$ lectin. A subset of vomeronasal fibers project into the glomerular layer of the sema $3 F^{-1-}(B)$ and syn- $1^{(r e /+}$ sema $3 F^{C / C}$ mice $(C)$. Arrows show the vomeronasal nerve. Insets show high$5(-/-)$; for syn- $1^{\text {(re/+ }}$ sema $F, n=3(+/ C), n=3(C / C) . D, E$, Vomeronasal sensory neuron axons innervate main olfactory EC lectin (green) $(D, F)$, anti-OMP (red) $(E, F)$, and Hoechst (blue) $(D-F)$. Vomeronasal axons entering the glomerular layer innervate main olfactory glomeruli, which are demarcated by periglomerular cells (arrows) identified by Hoechst nuclear staining.

vate glomeruli located on the medial, and occasionally the ventral and dorsal regions, of the MOB (Fig. 3D). The ectopically projecting axons usually appear to be a subset of the total number of sensory neuron axons terminating within a single MOB glomerulus (Fig. $3 D, E$ ).

Because sema3F is expressed in the mitral-tufted cell layer of the $\mathrm{MOB}$ and also in a subset of vomeronasal sensory neurons themselves, we examined the contribution of neuronal Sema3F to the fasciculation of the vomeronasal nerve and the segregation of main and accessory olfactory sensory neuron projections. Neuronal sema3F expression was selectively ablated by generating sema3F conditional null mice that express the Cre recombinase under the control of the pan-neuronal synapsin-1 promoter (Hoesche et al., 1993, 1995; Ma et al., 1999; Zhu et al. 2001; Sahay et al., 2003). In synapsin- ${ }^{\mathrm{Cre} /+}$; sema $3 F^{C / C}$ mice, the vomeronasal nerve is defasciculated (Fig. $2 C$ ), and a subset of vomeronasal axons invade the MOB (Fig. 3C). These defects are indistinguishable from those observed in sema $3 F^{-1-}$ mice. Together, these results show that neuronal Sema3F is required for fasciculation of the vomeronasal nerve and for segregation of sensory neuron projections of the main and accessory olfactory systems.

A small subset of $\mathrm{G} \boldsymbol{\alpha}_{\mathrm{i}}$-expressing vomeronasal neurons are mistargeted to the posterior AOB in sema $3 F^{-/-}$mice

The targeting of axons from apical vomeronasal sensory neurons within the $\mathrm{AOB}$ is dependent on Npn-2 (Fig. 4E,F) (Cloutier et al., 2002; Walz et al., 2002). The Npn-2 ligands Sema3F, Sema3B, 

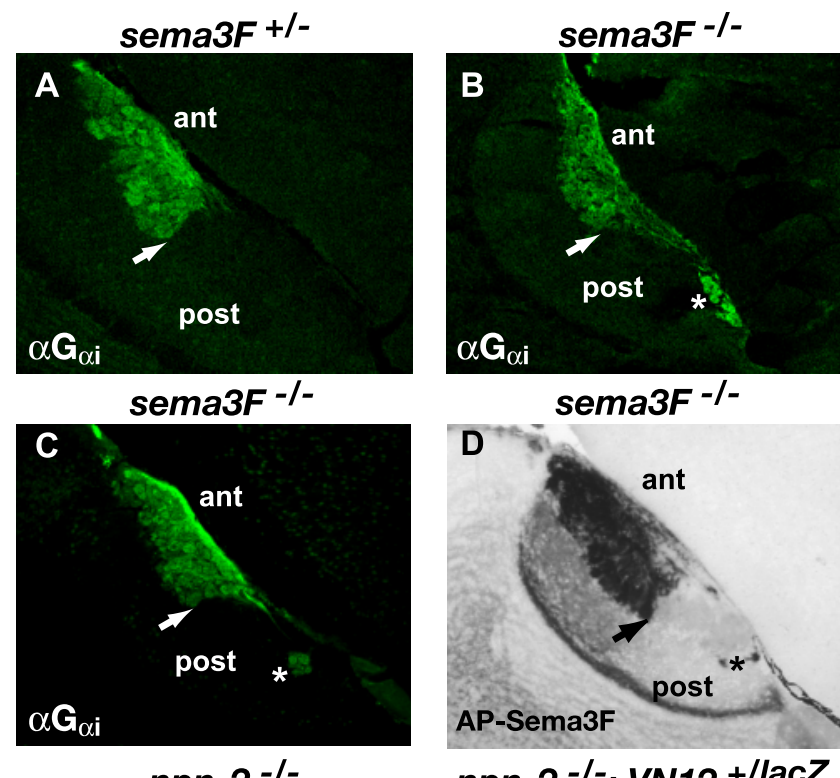

npn-2-/-
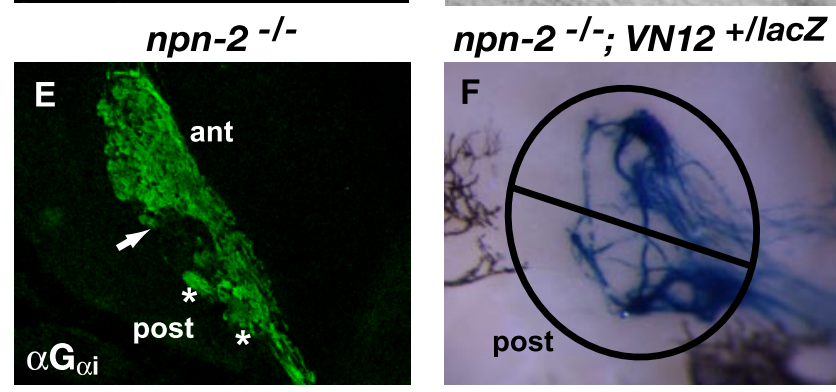

sema3F +/-; VN12 +/lacZ
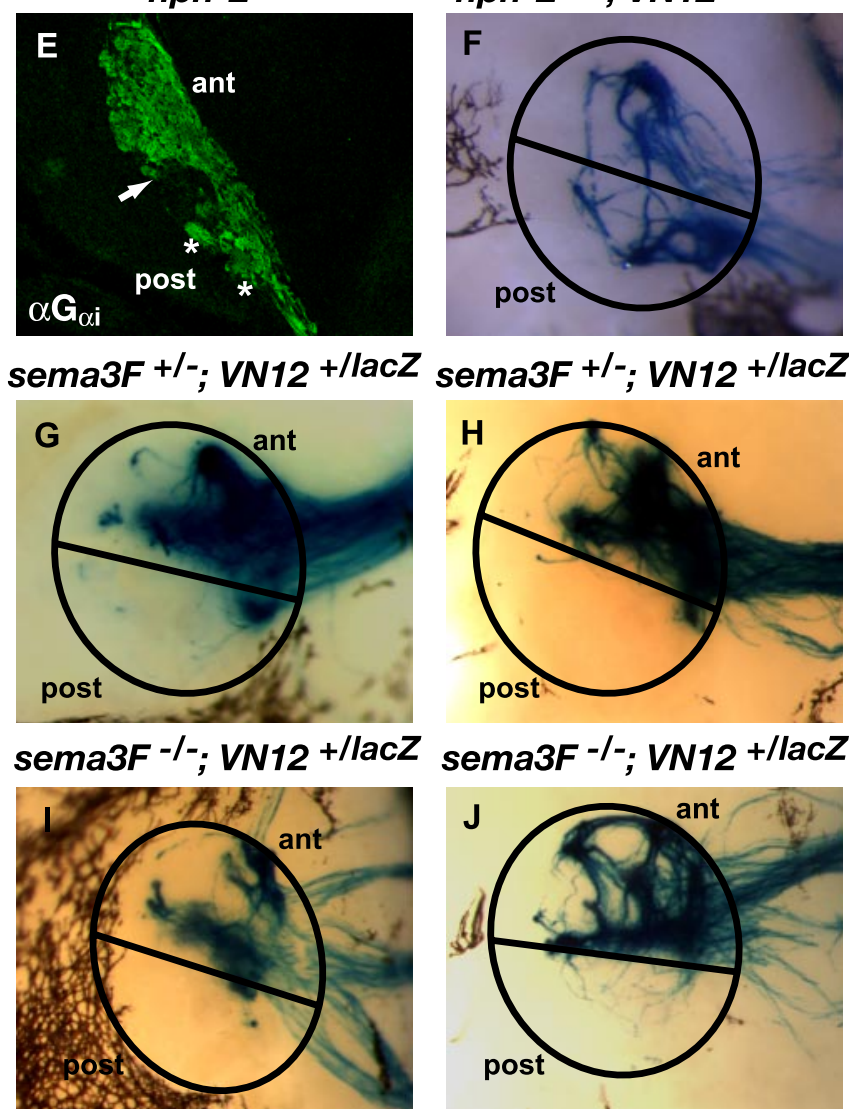

Figure 4. $\quad \mathrm{G} \alpha_{\mathrm{i} 2}$-expressing vomeronasal sensory neuron axons show partial loss of zonal targeting within the accessory olfactory bulb in sema $3 F^{-1-}$ mice. $A-E$, Parasagittal $A 0 B$ sections from 6- to 9-week-old $(A-C, E)$ or P10 $(D)$ sema3F $F^{+/-}(A)$, sema3F $F^{-/-}(B-D)$, and $n p n-2^{-/-}(E)$ mice stained with anti-G $\alpha_{\mathrm{i} 2}(A-C, E)$ or AP-Sema3F $(D)$. A small number of $\mathrm{G} \alpha_{\mathrm{i} 2}$-expressing vomeronasal sensory neuron axons (asterisk) ectopically innervate the posterior region of the $\mathrm{AOB}$ in some of the sema3F $F^{-1-}$ mice analyzed ( $n=5$ of a total of 8 mice analyzed). All sema $3 F^{+/-}$mice analyzed showed a normal pattern of innervation $(n=8)$. In contrast, all $n p n-2^{-/-}$mice $(n=3)$ analyzed showed extensive ectopic posterior AOB innervation by $\mathrm{G} \alpha_{\mathrm{i} 2}$-expressing vomeronasal sensory neuron axons. ant., Anterior AOB; post., posterior $A O B$. Arrow shows the anterior-posterior border in the $A O B$ as determined by $B S$ lectin staining (data not shown). $F-J$, Whole-mount high-magnification views of the $A O B$ stained with X-gal in 6- to 9-week-old $n p n-2^{-1-}(F)$, $\operatorname{sema3F}^{+/-} ; \operatorname{VN12^{+/lacZ}}(G, H)$, and ${\text { sema } 3 F^{-I-}}_{\text {VNN12 }}{ }^{+/ l a c Z}(I, J)$ mice. The AOB anterior-posterior boundary is indicated by a black and Sema3C are each expressed throughout the AOB, although their patterns of expression do not provide insight into the mechanism of zonal segregation of axons within the AOB (Cloutier et al., 2002). To test whether the Npn-2-dependent targeting of apical vomeronasal sensory neuron axons to the anterior $\mathrm{AOB}$ requires Sema3F, we examined the targeting of these neurons in sema3F $F^{-/-}$mice (Sahay et al., 2003). Parasagittal AOB sections from sema $3 F^{+/-}$, sema $3 F^{-/-}$, and $n p n-2^{-/-}$mice were stained with anti-G $\alpha_{\mathrm{i}}$ to visualize axons projecting from apical vomeronasal sensory neurons (Fig. $4 A-C, E$ ) and with Bandeiraea Simplicifolia (BS) lectin to identify the anterior-posterior border of the AOB (data not shown) (Tanaka et al., 1999). Although in sema $3 F^{+/-}$mice $\mathrm{G} \alpha_{\mathrm{i}}$-expressing vomeronasal axons are strictly targeted to the anterior half of the $\mathrm{AOB}$, a small number of fibers were found to innervate the posterior $\mathrm{AOB}$ in sema $3 \mathrm{~F}^{-/-}$mice (five of eight mice analyzed) (Fig. $4 A-C$ ). Similarly, we observe sparse ectopic posterior AOB innervation by $\mathrm{G} \alpha_{\mathrm{i}}$-expressing axons using AP-tagged Sema3F (AP-Sema3F) (Cloutier et al., 2002), which binds Npn-2-expressing vomeronasal neurons (three of three mice analyzed) (Fig. 4D). The observation that a small subset of $\mathrm{G} \alpha_{\mathrm{i}}$-expressing vomeronasal sensory neuron axons are mistargeted to the posterior $\mathrm{AOB}$ in sema $3 \mathrm{~F}^{-/-}$mice is in stark contrast to the severe loss of zonal segregation observed in $n p n-2^{-/-}$mice, in which a large proportion of $\mathrm{G} \alpha_{\mathrm{i}}$-expressing neurons are mistargeted to the posterior $\mathrm{AOB}$ in all mice analyzed (Fig. 4E) (Cloutier et al., 2002; Walz et al., 2002).

We next analyzed targeting of a subset of apical vomeronasal sensory neuron axons using whole-mount X-gal staining of AOBs from sema3F; VN12 $2^{+ \text {llacZ }}$ mice. As shown previously, a large proportion of VN12-expressing axons ectopically innervate the posterior region of the $\mathrm{AOB}$ in the absence of Npn-2 (Fig. $4 F$ ) (Cloutier et al., 2002); however, VN12-expressing vomeronasal neurons are correctly targeted to the anterior AOB in sema $3 F^{+/-}$; $V N 12^{+/ l a c Z}$ and sema3 $F^{-/-} ; V N 12^{+/ l a c Z}$ mice (Fig. 4G-J). In only 2 of $10{\text { sema } 3 F^{-/-}}^{-}$VN12 ${ }^{+/ \text {lacZ }}$ mice analyzed, one small LacZpositive glomerulus was observed in the posterior region of the AOB (Fig. 4I). Thus, although Sema3F mediates Npn-2dependent vomeronasal nerve fasciculation, this secreted semaphorin plays only a minor role in Npn-2-dependent targeting of $\mathrm{G} \alpha_{\mathrm{i}}$-expressing vomeronasal sensory neuron axons to the anterior $\mathrm{AOB}$.

A subset of main olfactory sensory axons in $s e m a 3 F^{-/-}$mice fails to retract after overshooting the glomerular layer of the main olfactory bulb

Akin to vomeronasal sensory neurons in the accessory olfactory system, a subset of main olfactory sensory neurons express Npn-2 and target to regionally segregated glomeruli within the MOB (Fig. 5B,D) (Norlin and Berghard, 2001; Cloutier et al., 2002; Walz et al., 2002). The expression patterns of sema3F and other Npn-2 ligands such as sema3B and sema3C in the developing MOB suggests that secreted semaphorins play a role in the establishment of the precise primary olfactory receptor neuron connections within the MOB (Fig. $5 \mathrm{~A}, \mathrm{C}$ ) (Cloutier et al., 2002; Walz et al., 2002). The establishment of the adult pattern of glomerular innervation within the mouse $\mathrm{MOB}$ is likely to be achieved

line. In $n p n-2^{-/-}$mice, a large proportion of VN12-expressing vomeronasal sensory neuron axons are misrouted to the posterior $\mathrm{AOB}(F)(n=3)$ (Cloutier et al., 2002). In contrast, VN12expressing vomeronasal sensory neuron axons are restricted to the anterior half of the $A 0 B$ in sema3F $F^{+/-} ; \operatorname{VN12}{ }^{+/ l a c Z}(G, H)(n=8)$ and sema3F $F^{-/-} ; \operatorname{VN12}{ }^{+/ l a c Z}(I, J)(n=8)$. 
through remodeling of axonal projections after exuberant growth within and beyond glomerular targets (Tenne-Brown and Key, 1999). Axons overshooting the glomerular layer during early development disappear by postnatal day 5.5 (P5.5), resulting in the adult pattern of glomerular innervation. The presence of aberrant primary olfactory sensory neuron axons deep within the external plexiform layer of the main olfactory bulb of adult $n p n-2^{-/-}$ mice suggests a deficit in axonal pruning (Cloutier et al., 2002; Walz et al., 2002).

To test whether Sema3F-Npn-2 signaling is required for pruning of main olfactory sensory neuron axons within the $\mathrm{MOB}$, parasagittal sections of MOBs from sema $3 F^{+/-}$and sema $3 F^{-/-}$mice at P1.5 and P10 were stained with anti-OMP to visualize primary olfactory projections in the main olfactory bulb. At P1.5 in both sema $3 F^{+/-}$and sema3F $F^{-/-}$mice, we observes a subset of OMP-positive fibers overshooting the glomerular layer and terminating in the external plexiform layer (EPL) (Fig. 5E-H). By P10, OMP-positive olfactory axons are no longer observed in the EPL of sema3F $F^{+/-}$MOB (Fig. 5I). In contrast, a significant number of OMPpositive fibers are still present in $\mathrm{P} 10$ sema $3 F^{-1-}$ mice (Fig. $5 \mathrm{~J}, \mathrm{~K}$ ). Although the majority of overshooting axons in sema $3 F^{-/-}$mice have disappeared by P30 (data not shown), a small number of axons persist in the EPL throughout adulthood (Fig. $5 L$ ), as observed previously in $n p n$ $2^{-1-}$ mice (Walz et al., 2002). These results suggest that Sema3FNpn-2 signaling is critical for retraction or pruning of main olfactory sensory axons.

\section{Mistargeting of $\mathrm{G} \alpha_{\mathrm{o}}$-expressing vomeronasal axons to the anterior accessory olfactory bulb in \\ slit-1 ${ }^{-/-}$mice}

Although Npn-2 is required in vivo for targeting of apical vomeronasal projections to the anterior $\mathrm{AOB}$, the guidance cues involved in targeting basal vomeronasal sensory neuron projections to the posterior $\mathrm{AOB}$ remain to be identified. Interestingly, slit proteins are expressed in both the $\mathrm{VNO}$ and $\mathrm{AOB}$, and also in a subset of mitral cells in the MOB (Marillat et al., 2002; Knoll et al., 2003). Furthermore, the slit receptor, Robo-2, is restricted in its expression to basal vomeronasal sensory neurons (Marillat et al., 2002; Knoll et al., 2003) (Fig. $1 B$ ). Finally, within the VNO, slit-1 and slit-3 show highest levels of expression within apically located sensory neurons, which project their axons to the anterior AOB (Fig. 1D-F) (Marillat et al., 2002; Knoll et al., 2003). These slit and Robo expression patterns, coupled with the ability of Slit-1 to repel vomeronasal neurons in vitro (Knoll et al., 2003), suggest that Slit-1-Robo-2 signaling mediates targeting and fasciculation of basal vomeronasal projections to the posterior AOB.

To evaluate the role of Slit-1 in maintaining the integrity of basal vomeronasal sensory neuron projections, we stained MOB coronal sections from slit- $1^{+/-}$and slit- $1^{-/-}$mice (Plump et al., 2002) with EC lectin to visualize vomeronasal axons. In both
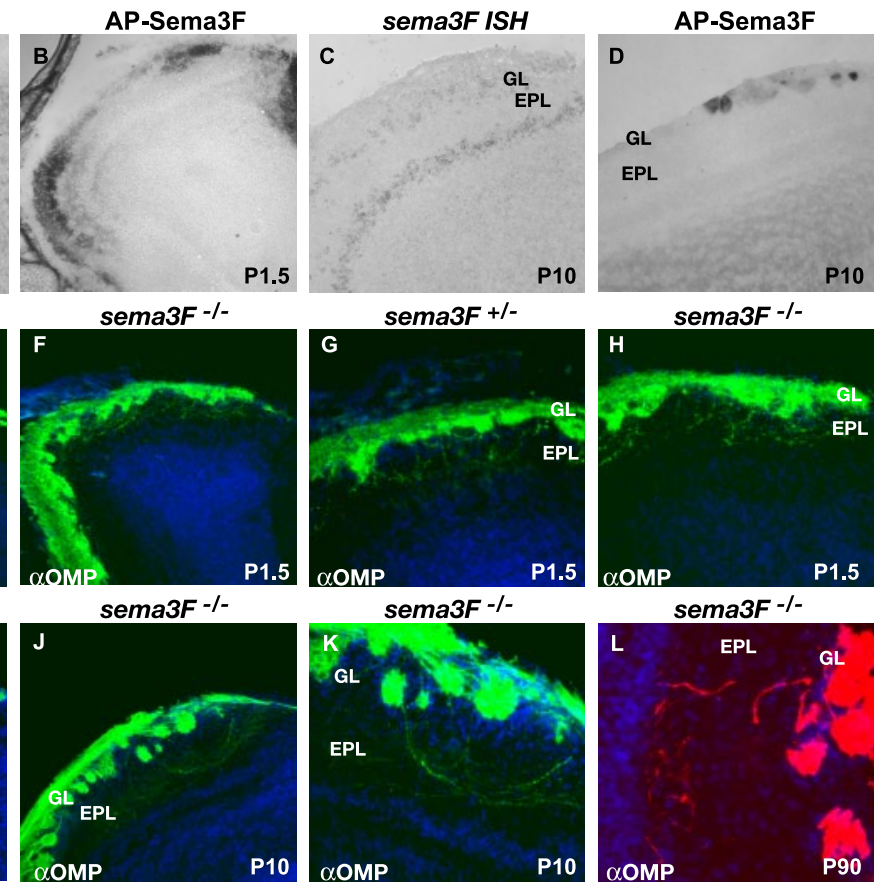

Figure 5. A subset of main olfactory sensory neuron axons overshoot the MOB glomerular layer and fail to retract in sema $3 F^{-1-}$ mice. $A, C$, sema3F is expressed in the MOB. In situ hybridization of MOB parasagittal sections at $P 1.5(A)$ and $P 10(C)$ CRNA probes specific for sema3F. At P1.5, sema3F expression is observed in the M0B mitral-tufted cell layer. By P10, sema3 specific regions of the MOB. Parasagittal MOB sections from P1.5 $(B)$ or P10 $(D)$ mice stained with AP-Sema3F. Npn-2-expressing

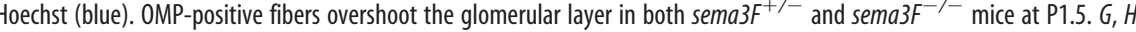
Higher magnifications of $E$ and $F$, respectively. In contrast, at P10 (I-K) and P90 ( $L$ ) (data not shown), 0MP-positive axons overshooting the glomerular layer are observed in sema3 $\mathrm{F}^{-/-}$mice $(J-L)$ but not in sema $3 \mathrm{~F}^{+/-}$mice $(I)$ (data not shown). $K$, High-magnification view of $J . n=4$ each for sema3F $F^{+/-}$and sema3F $F^{-/-}$at P1.5, P10, and P60.

slit- $1^{+/-}$and slit $-1^{-/-}$mice, the vomeronasal nerve was tightly fasciculated (Fig. $6 A, B$ ). To further assess basal vomeronasal sensory neuron axonal fasciculation, slit- $1^{+/-}$and $s$ lit $-1^{-/-}$mice expressing tau-lacZ in a subpopulation of basal vomeronasal sensory neurons under the control of the promoter for the V2R receptor EC2 were generated. Whole-mount X-gal staining of olfactory bulbs from slit-1 ${ }^{+/-} ; E C 2^{+/ \text {tau-lacZ }}$ and slit-1 $1^{-/-}$; $E C 2^{+/ t a u-l a c Z}$ mice showed that the integrity of EC2-positive vomeronasal projections along the medial surface of the MOB is intact in mice lacking Slit-1 (Fig. 6C,D). Therefore, Slit-1 is dispensable for fasciculation of the vomeronasal nerve, for segregation of accessory and main olfactory projections, and for guiding vomeronasal axons to the AOB.

Because the Slit-1 receptor Robo-2 is restricted to basally located vomeronasal sensory neurons, we examined the fidelity of $\mathrm{G} \alpha_{\mathrm{o}}$-expressing basal vomeronasal axonal targeting to the posterior AOB in slit- $1^{-1-}$ mice. Parasagittal sections of AOBs from slit $-1^{+/-}$and slit- $1^{-/-}$mice were stained with $\mathrm{G} \alpha_{\mathrm{o}}$ antibodies (Fig. 7A-C) and BS lectin (data not shown). In contrast to wildtype and slit- $1^{+/-}$mice (Fig. 7A) (data not shown), in which $\mathrm{G} \alpha_{\mathrm{o}}$-positive axons are targeted to the posterior region of the $\mathrm{AOB}$, slit $1^{-/-}$mice exhibit ectopic innervation of the anterior $\mathrm{AOB}$ by $\mathrm{G} \alpha_{\mathrm{o}}$-expressing vomeronasal axons (Fig. $7 \mathrm{~B}, \mathrm{C}$ ). We next performed whole-mount X-gal staining on AOBs from slit- $1^{+/+}$; $E C 2^{+/ \text {lacZ }}$, slit-1 ${ }^{+/-} ; E C 2^{+/ \text {lacZ }}$, and Slit $-1^{-/-} ; E C 2^{+ \text {/lacZ }}$ mice to visualize $\mathrm{AOB}$ targeting by the subset of basal vomeronasal sensory neurons that express the EC2 receptor. In all slit- $1^{+/+}$mice 


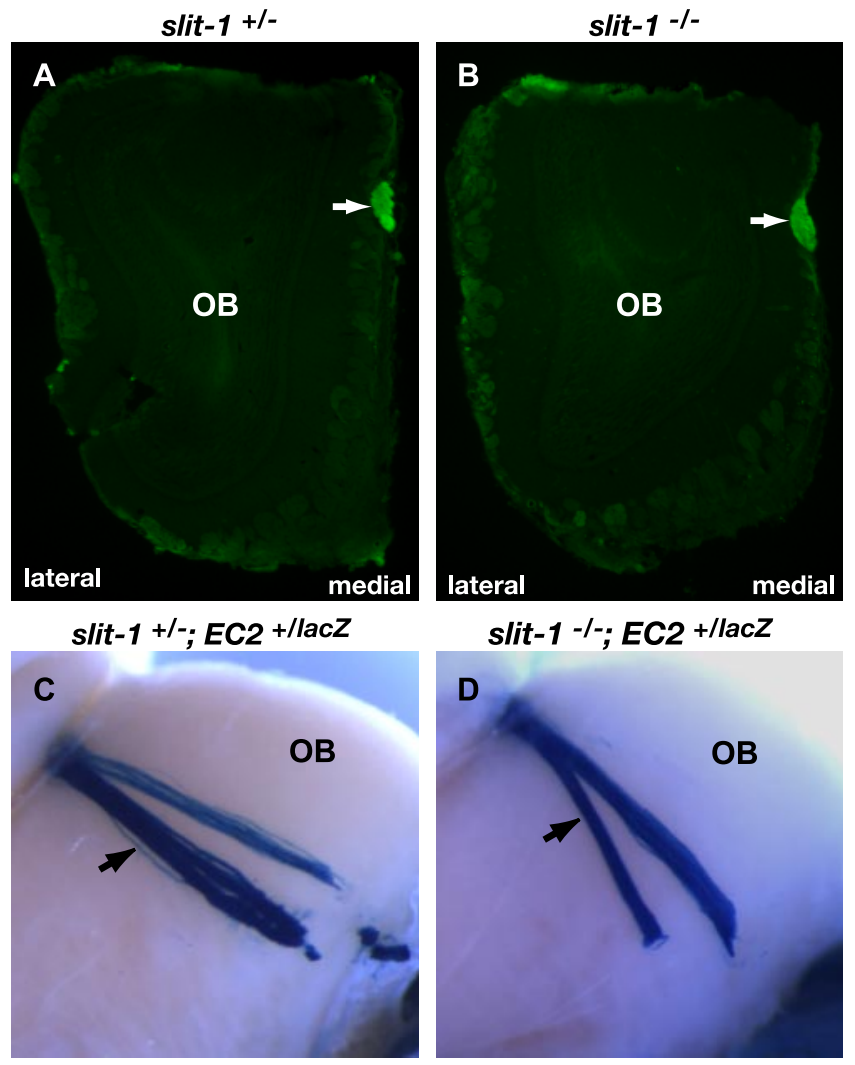

Figure 6. The vomeronasal nerve remains tightly fasciculated in slit- $1^{-/-}$mice. $A, B$, Coronal sections of olfactory bulbs at similar rostral-caudal axis levels from 9-week-old slit- ${ }^{+/-}$ $(A)$ and $s$ lit- $1^{-1-}(B)$ mice stained with $\mathrm{EC}$ lectin. The vomeronasal nerve is tightly fasciculated in both slit- ${ }^{+/-}(A)$ and slit- $1^{-/-}(B)$ mice. Arrow points to the vomeronasal nerve. $n=2$ $(+/+), n=4(+/-), n=4(-/-) . C, D$, Whole-mount high-magnification views of primary vomeronasal sensory neuron projections stained with $\mathrm{X}$-gal in 7 -week-old slit- $1^{+/-}$ $(C)$ and slit- $1^{-/-}(D)$ mice. The arrow points to vomeronasal fibers growing along the medial surface of the MOB toward the AOB. Tightly fasciculated axon bundles are observed in both slit $-1^{+/-}(C)$ and slit $-1^{-/-}(D)$ mice. $n=2(+/+), n=3(+/-), n=3(-/-)$.

examined, lacZ-positive fibers targeted exclusively to the posterior $\mathrm{AOB}$ (Fig. $7 E)(n=8)$. In the majority of slit-1 ${ }^{+/-} ; E C 2^{+/ t a u-}$ lac $Z$ mice analyzed (12 of 16), all lacZ-positive axons were also correctly targeted to the posterior AOB (Fig. 7F). In 4 of these 16 heterozygous slit-1 mice, modest ectopic innervation of the anterior AOB was observed (Fig. $7 G$ ). In contrast, all slit-1 ${ }^{-/-} ; E C 2^{+/}$ tau-lac $Z$ mice analyzed showed that a substantial fraction of the lacZ-positive axons ectopically innervated the anterior AOB (Fig. $7 H-J)(n=12)$. Together, these results show that Slit-1 is dispensable for fasciculation of $\mathrm{G} \alpha_{\mathrm{o}}$-expressing vomeronasal axons but is critical for targeting of these axons within the AOB to their posterior glomeruli.

\section{Discussion}

Directing primary sensory afferent projections to their discrete central targets is essential for generating distinct topographic maps. The expression of secreted semaphorin and slit guidance cues in the perinatal and early postnatal accessory and main olfactory systems suggests that these cues are required for disparate developmental processes, including fasciculation, segregation, and targeting of primary olfactory sensory axons. It is likely that coordinated regulation of these processes by different guidance cues gives rise to the mature glomerular maps observed in the accessory and main olfactory systems. Consistent with this notion, vomeronasal neurons of the accessory olfactory system are responsive to selective secreted semaphorins and slits in vitro (Cloutier et al., 2002; Knoll et al., 2003). Furthermore, both the secreted semaphorin receptor Npn-2 and the slit receptor Robo-2 are expressed in complementary populations of spatially segregated sensory neurons in the VNO (Cloutier et al., 2002; Knoll et al., 2003). Analysis of $n p n-2^{-1-}$ mice suggests a role for Npn-2 ligands in fasciculation, targeting, and segregation of vomeronasal sensory axons and also lamina-specific innervation of main olfactory sensory axons (Cloutier et al., 2002; Walz et al., 2002). Our results here show that Sema3F is critical for Npn-2-mediated fasciculation of the vomeronasal nerve and for segregation of projections of the main and accessory olfactory systems; however, Sema3F only plays a minor role in the Npn-2-dependent targeting of apical vomeronasal axons to the anterior AOB. In striking contrast, Slit-1 is not necessary for fasciculation of vomeronasal projections but is required for the precise targeting of basal vomeronasal axons to the posterior AOB. In the main olfactory system, Sema3F is required for retraction of main olfactory sensory axons in the MOB during early development of the adult glomerular map. Together, our results reveal distinct and complementary roles for two families of repellents, the secreted semaphorins and the slits, in controlling axonal fasciculation, targeting, retraction, and segregation of olfactory sensory projections.

\section{Sema3F-Npn-2 signaling promotes fasciculation of the vomeronasal nerve}

Vomeronasal axons are tightly fasciculated as they project along the medial surface of the MOB en route to the AOB. Analysis of $n p n-2^{-1-}$ mice reveals a critical role for Npn-2 in promoting fasciculation of the vomeronasal nerve. At least two possible mechanisms by which Npn-2 mediates this fasciculation can be envisaged. Npn-2-expressing vomeronasal axons could respond to secreted semaphorins or other ligands expressed on the medial surface of the MOB, leading to their fasciculation through a "surround repulsion" mechanism (Cloutier et al., 2002). Alternatively, vomeronasal sensory neuron axonal fasciculation could depend on Npn-2-dependent adhesive interactions among Npn2-positive axons. The expression of the Npn-2 ligand Sema3F in mitral cells of the medial region of the MOB, coupled with the repulsive effect of Sema3F observed on vomeronasal axons in vitro, suggests that this secreted semaphorin controls Npn-2dependent fasciculation of the vomeronasal nerve through surround repulsion (Cloutier et al., 2002). Indeed, the dramatic defasciculation of the vomeronasal nerve that we observe in sema $3 F^{-1-}$ mice, which is identical to that observed in $n p n-2^{-/-}$ mice, indicates that Sema3F-Npn-2 signaling is required to drive fasciculation of the vomeronasal nerve in vivo. Furthermore, our results show that other secreted semaphorins cannot compensate for the lack of Sema3F in vivo.

The relationship between axonal fasciculation and targeting is not simple. Recent work on the establishment of thalamocortical connectivity shows that thalamic axons destined for distinct cortical targets are topographically organized en passant within the internal capsule (Garel et al., 2002; Dufour et al., 2003; Seibt et al., 2003). Implicit in these findings is the importance of selective fasciculation and spatial distribution along intermediate target regions of thalamocortical efferents for correct targeting of these axons. The striking fasciculation defect that we observe in $s e m a 3 F^{-/-}$mice suggests that not all topographic mapping has such requirements. Despite profound defasciculation, most of the apical vomeronasal sensory neuron axons in sema $3 F^{-1-}$ mice reach the $\mathrm{AOB}$ and, importantly, accurately innervate their ap- 
slit-1+/-

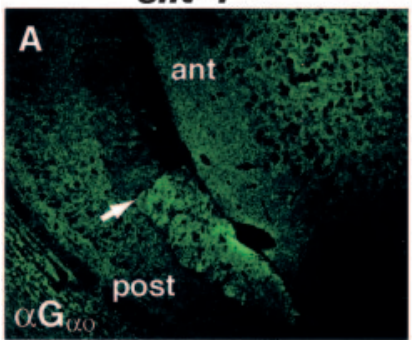

slit-1-/-

slit-1+/+; EC2+/lacZ

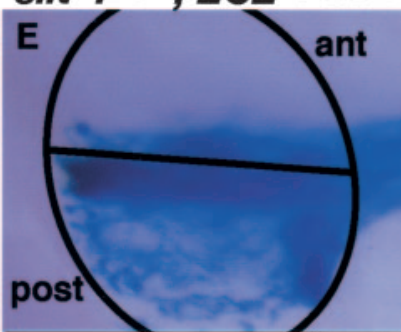

slit-1+l-; EC2+/lacZ

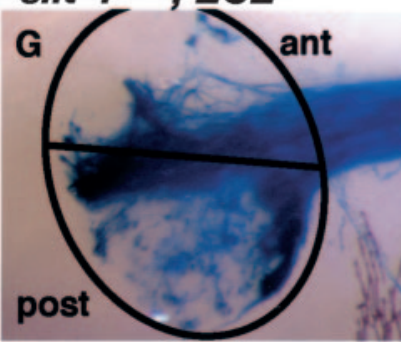

slit-1-/-; EC2+/lacZ

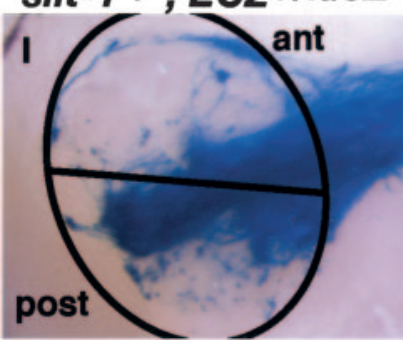

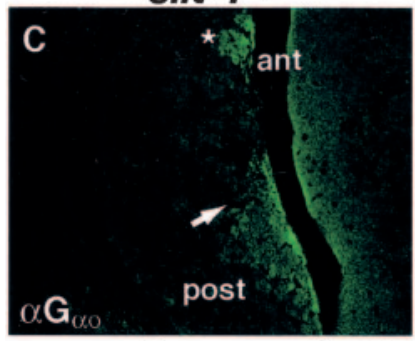

slit-1-/-

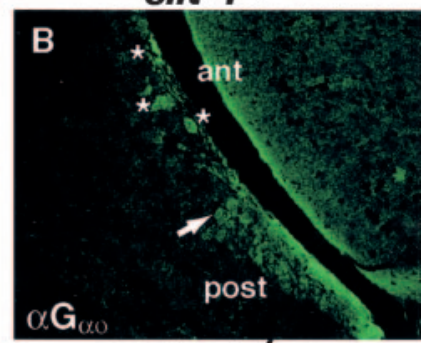

slit-1-1-

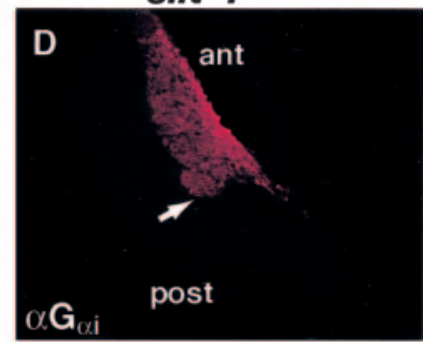

slit-1+/-; EC2+/lacZ
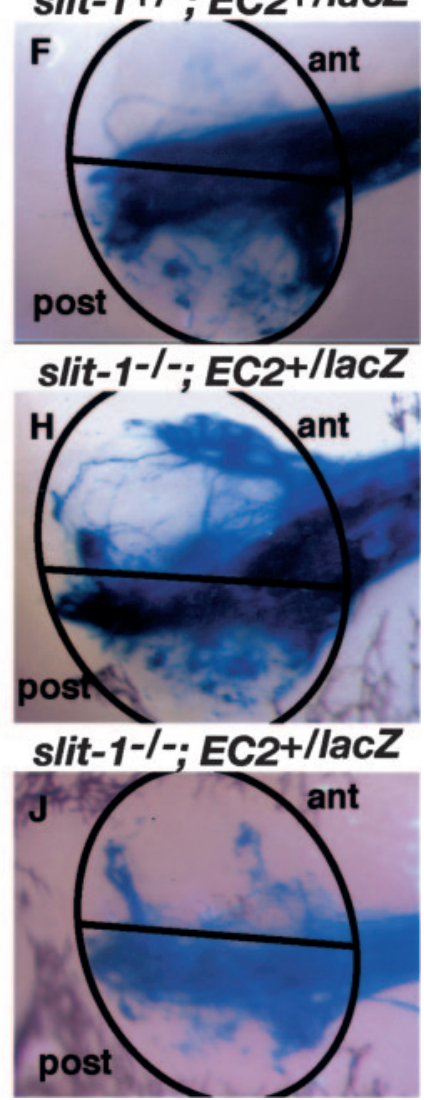

Figure 7. $G \alpha_{0}$-expressing vomeronasal sensory neurons axons show loss of zonal targeting within the accessory olfactory bulb in slit- $1^{-1-}$ mice. $A-D$, Parasagittal $A O B$ sections from 6- to 9-week-old slit- $1^{+/-}(A)$ and slit-1 $1^{-/-}(B-D)$ mice stained with anti-G $\alpha_{0}(A-C)$ or anti-G $\alpha_{\mathrm{i}}$ (D). Projections of $\mathrm{G} \alpha_{0}$-expressing vomeronasal sensory neuron axons are restricted to the posterior half of the $A O B$ in slit- $1^{+/-}$mice $(A)(n=4)$, whereas many of these fibers innervate the anterior region of the $A O B$ (asterisk) in all slit- ${ }^{-1-}$ mice $(B, C$ analyzed $(n=4) . B, C$, Sections from two different slit- $1^{-/-}$mice. In contrast to $\mathrm{G} \alpha_{0}$-expressing vomeronasal sensory neuron axons, $\mathrm{G} \alpha_{\mathrm{i}}$-expressing vomeronasal sensory neuron axons are restricted to the anterior region of the $A O B$ in slit- $1^{-1-}$ mice $(D)(n=3)$. Arrow shows the anterior-posterior border in the $A O B . E-J$, Whole-mount high-magnification views of the $A O B$ stained with $X$-gal in 5 - to 9-week-old slit- $1^{+/+} ; E C 2^{+/ \text {lacZ }}(E)$, slit- $1^{+/-} ; E C 2^{+/ l a c Z}(F, G)$, and slit-1 ${ }^{-/-} ; E C 2^{+ \text {/lacz }}$ $(H-J)$ mice. The $A O B$ is circled in black; the prospective anterior-posterior $A O B$ boundary is indicated with a black line. Axons from vomeronasal sensory neurons that express the EC2 propriate AOB target regions. Therefore, fasciculation and targeting of vomeronasal axons in the accessory olfactory system are independent; vomeronasal nerve fasciculation is neither necessary nor sufficient for vomeronasal sensory neuron axonal targeting in the AOB. Furthermore, slit- $1^{-/-}$mice show profound targeting defects in the $\mathrm{AOB}$ despite intact fasciculation of the vomeronasal nerve. Therefore, it is unlikely that topographic organization of axons exists in the mouse vomeronasal nerve, as has been observed in the rabbit vomeronasal nerve (Mori et al., 1987).

\section{Sema3F-Npn-2 signaling modulates laminar targeting of} main olfactory sensory axons

Main olfactory sensory neurons, like their counterparts in the accessory olfactory system, project their axons to the MOB in a stereotypic manner. Sema3A has been implicated in the targeting of npn-1-expressing main olfactory neurons to the MOB (Schwarting et al., 2000, 2004; Taniguchi et al., 2003). Our analysis in sema3F $F^{-1-}$ mice suggests that Sema3F is not required for the zonal targeting of Npn-2-expressing main olfactory sensory axons to the MOB (data not shown). Rather, our results reveal a role for Sema3F in fine-tuning laminar selection required for establishment of the adult pattern of glomerular innervation. The persistence of main olfactory sensory axons in the EPL of the $\mathrm{MOB}$ in sema $3 \mathrm{~F}^{-/-}$mice suggests that Sema3F-Npn-2 signaling is normally involved in the pruning of these exuberant projections. The expression of sema3F in mitral-tufted cells and in periglomerular cells may contribute to the retraction of main olfactory sensory axons. Because Npn-2 is found at both P0 and $\mathrm{P} 10$ in main olfactory sensory axons and Sema3F is observed in the MOB at these same developmental times, Sema3F-Npn-2 signaling alone is unlikely to explain this temporally regulated pruning event. It is plausible that specific plexins or plexin effectors might modulate Npn-2 function and regulate main olfactory sensory axon pruning by Sema3F. Interestingly, a role for Sema3F-Npn-2/Plexin-A3 signaling has been proposed for pruning of the infrapyramidal tract in the hippocampus (Bagri et al., 2003).

Secreted semaphorins and slits control anterior-posterior targeting of vomeronasal axons in the AOB

The spatially restricted and complementary expression of the secreted semaphorin and slit receptors Npn-2 and Robo-2, respectively, in vomeronasal sensory neurons suggests that their ligands govern the formation of stereotypic connections within the $\mathrm{AOB}$ (Cloutier et al., 2002; Knoll et al., 2003). Npn-2, which is expressed in apical vomeronasal sensory neurons, is required for the targeting of apical vomeronasal neuron axons to the anterior AOB (Cloutier et al., 2002; Walz et al., 2002). In contrast, only a small number of apical vomeronasal axons improperly project to the posterior $\mathrm{AOB}$ in sema3 $\mathrm{F}^{-/-}$mice. It is unclear whether these mistargeted axons emanate from specific subpopulations of apical sensory neurons in the VNO, so it remains possible that sema3F expression is required for the guidance of a very small subset of apical vomeronasal neurons. Consistent with this no-

receptor, visualized here using $X$-gal staining, are restricted to the posterior half of the $A O B$ in slit- $1^{+/+}$mice $(E)(n=6)$. In the majority of slit- ${ }^{+/-}$mice analyzed ( $n=12$ of 16 analyzed) $(F)$, EC2-positive axons are restricted to the posterior $\mathrm{AOB}$; however, a small number of $\mathrm{EC2}-$ positive fibers are observed in the anterior AOB of some slit- $1^{+/-}$mice $(G)(n=4$ of 16 analyzed). In contrast, a subset of E(2-positive vomeronasal axons innervate the anterior half of the AOB in all slit- $1^{-/-}$mice analyzed $(H-J)(n=12)$. 
tion, the targeting of apical VN12-expressing vomeronasal sensory neuron axons to the anterior $\mathrm{AOB}$ appears to be unaffected in $s e m a 3 F^{-/-}$mice, in striking contrast to what we observe in $n p n-2^{-1-}$ mice (Cloutier et al., 2002; this study). Therefore, in addition to Sema3F, other unidentified Npn-2 ligands must also control Npn-2-dependent targeting of apical vomeronasal neurons. Slit axon guidance cues are attractive candidates for mediating targeting of basal vomeronasal axons to the posterior $\mathrm{AOB}$ based on their pattern of expression in the accessory olfactory system and their ability to repel vomeronasal neurons in vitro (Marillat et al., 2002; Knoll et al., 2003). Our results show that a subset of basal vomeronasal sensory neuron projections improperly project to the anterior $\mathrm{AOB}$ in $s$ lit $1^{-/-}$mice, suggesting that Slit-1 plays a role in the guidance of these axons to the posterior AOB. Because a large proportion of basal vomeronasal sensory neuron axons still target correctly in slit $1^{-/-}$mice, it is likely that other Slits are also involved in modulating the segregation of V2R-expressing axons.

One possible mechanism underlying targeting of V2Rpositive vomeronasal axons to the posterior $\mathrm{AOB}$ relies on the asymmetric expression of slit-1 in the AOB so that Robo-2expressing basal vomeronasal sensory neuron axons are repelled away from the anterior region of the AOB. In support of this model, Slit-1 repels vomeronasal neuronal processes in vitro and is expressed in mitral cells at the anterior tip of the AOB. Slit-1 may contribute to the formation of a slit protein gradient in the AOB (Knoll et al., 2003). An alternative possibility is that cues secreted by AOB afferents themselves, which arise in either the apical or basal sensory epithelium, drive axonal targeting in a reciprocal manner. For example, it is possible that the spatially restricted expression of Slit-1 in apical vomeronasal neurons during development leads to segregation of Robo-2-expressing basal vomeronasal axons to the posterior AOB. This complementary expression of Slit-1 and Robo-2 may contribute to the segregation of these two populations of axons through repulsion once they reach the AOB. Genetic ablation of slit-1 exclusively in vomeronasal sensory neurons will be required to test this possibility. Interestingly, a similar mechanism of action may be involved in mediating the Npn-2-dependent segregation of apical vomeronasal axons to the anterior AOB. A recent analysis of $s e m a 3 B$ expression in sema3B-GFP BAC transgenic animals shows that expression of $s e m a 3 B$ is restricted primarily to basal vomeronasal sensory neurons (Gong et al., 2003). The complementary patterns of expression of Npn-2 and Sema3B in apical and basal subpopulations of vomeronasal neurons, respectively, may therefore contribute to the targeting of apical vomeronasal neuron axons to the anterior AOB. Although our preliminary results suggest that apical vomeronasal neurons project correctly in sema $3 B^{-/-}$mice (data not shown), further analysis using sema3F/sema $3 B$ double mutants will be required to determine whether combinations of secreted semaphorins expressed in the VNO modulate targeting of apical vomeronasal neurons.

Secreted semaphorins and slits join the ephrins as important cues for establishing the glomerular map in the accessory olfactory system. It is likely that a combination of attractive and repulsive cues in the AOB, and possibly in vomeronasal sensory neurons themselves, allows for precise targeting of these sensory afferent projections to either posterior or anterior regions of the AOB. Further studies will address the specific sources of these secreted cues and potential interplay between axon guidance molecules and vomeronasal sensory neuron receptors in the development of connectivity in the accessory olfactory system.

\section{References}

Bagri A, Cheng HJ, Yaron A, Pleasure SJ, Tessier-Lavigne M (2003) Stereotyped pruning of long hippocampal axon branches triggered by retraction inducers of the semaphorin family. Cell 113:285-299.

Belluscio L, Koentges G, Axel R, Dulac C (1999) A map of pheromone receptor activation in the mammalian brain. Cell 97:209-220.

Buck LB (2000) The molecular architecture of odor and pheromone sensing in mammals. Cell 100:611-618.

Cloutier JF, Giger RJ, Koentges G, Dulac C, Kolodkin AL, Ginty DD (2002) Neuropilin-2 mediates axonal fasciculation, zonal segregation, but not axonal convergence, of primary accessory olfactory neurons. Neuron 33:877-892.

Dufour A, Seibt J, Passante L, Depaepe V, Ciossek T, Frisen J, Kullander K, Flanagan JG, Polleux F, Vanderhaeghen P (2003) Area specificity and topography of thalamocortical projections are controlled by ephrin/Eph genes. Neuron 39:453-465.

Dulac C, Axel R (1995) A novel family of genes encoding putative pheromone receptors in mammals. Cell 83:195-206.

Dulac C, Torello AT (2003) Molecular detection of pheromone signals in mammals: from genes to behaviour. Nat Rev Neurosci 7:551-562.

Garel S, Yun K, Grosschedl R, Rubenstein JL (2002) The early topography of thalamocortical projections is shifted in Ebf1 and Dlx1/2 mutant mice. Development 129:5621-5634.

Giger RJ, Urquhart ER, Gillespie SKH, Levengood DV, Ginty DD, Kolodkin AL (1998) Neuropilin-2 is a receptor for semaphorin IV: insight into the structural basis of receptor function and specificity. Neuron 21:1079-1092.

Gong S, Zheng C, Doughty ML, Losos K, Didkovsky N, Schambra UB, Nowak NJ, Joyner A, Leblanc G, Hatten ME, Heintz N (2003) A gene expression atlas of the central nervous system based on bacterial artificial chromosomes. Nature 425:917-925.

Halpern M (1987) The organization and function of the vomeronasal system. Annu Rev Neurosci 10:325-362.

Halpern M, Shapiro LS, Jia C (1995) Differential localization of G proteins in the opossum vomeronasal system. Brain Res 677:157-161.

Halpern M, Jia C, Shapiro LS (1998) Segregated pathways in the vomeronasal system. Microsc Res Tech 41:519-529.

Herrada G, Dulac C (1997) A novel family of putative pheromone receptors in mammals with a topographically organized and sexually dimorphic distribution. Cell 90:763-773.

Hoesche C, Sauerwald A, Veh RW, Krippl B, Kilimann MW (1993) The 5 '-flanking region of the rat synapsin I gene directs neuron-specific and developmentally regulated reporter gene expression in transgenic mice. J Biol Chem 268:26494-26502.

Hoesche C, Bartsch P, Kilimann MW (1995) The CRE consensus sequence in the synapsin I gene promoter region confers constitutive activation but no regulation by cAMP in neuroblastoma cells. Biochim Biophys Acta 1261:249-256.

Jia C, Halpern M (1996) Subclasses of vomeronasal receptor neurons: differential expression of sensory axons in Manduca sexta. J Neurosci 23:11523-11538.

Knoll B, Zarbalis K, Wurst W, Drescher U (2001) A role for the EphA family in the topographic targeting of vomeronasal axons. Development 128:895-906.

Knoll B, Schmidt H, Andrews W, Guthrie S, Pini A, Sundaresan V, Drescher U (2003) On the topographic targeting of basal vomeronasal axons through Slit-mediated chemorepulsion. Development 130:5073-5082.

Ma L, Reis G, Parada LF, Schuman EM (1999) Neuronal NT-3 is not required for synaptic transmission or long-term potentiation in area CA1 of the adult rat hippocampus. Learn Mem 6:267-275.

Marillat V, Cases O, Nguyen-Ba-Charvet KT, Tessier-Lavigne M, Sotelo C, Chedotal A (2002) Spatiotemporal expression patterns of slit and robo genes in the rat brain. J Comp Neurol 442:130-155.

Matsunami H, Buck LB (1997) A multigene family encoding a diverse array of putative pheromone receptors in mammals. Cell 90:775-784.

Mombaerts P (2001) How smell develops. Nat Neurosci [Suppl] 4:1192-1198.

Mombaerts P, Wang F, Dulac C, Chao SK, Nemes A, Mendelsohn M, Edmondson J, Axel R (1996) Visualizing an olfactory sensory map. Cell 87:675-686.

Mori K, Imamura. K., Fujita SC, Obata K (1987) Projections of two subclasses of vomeronasal nerve fibers to the accessory olfactory bulb in the rabbit. Neuroscience 20:259-278.

Norlin EM, Berghard A (2001) Spatially restricted expression of regulators 
of G-protein signaling in primary olfactory neurons. Mol Cell Neurosci 17:872-882.

Pantages E, Dulac C (2000) A novel family of candidate pheromone receptors in mammals. Neuron 28:835-845.

Plump AS, Erskine L, Sabatier C, Brose K, Epstein CJ, Goodman CS, Mason CA, Tessier-Lavigne M (2002) Slit1 and Slit2 cooperate to prevent premature midline crossing of retinal axons in the mouse visual system. Neuron 33:219-232.

Rodriguez I, Del Punta K, Rothman A, Ishii T, Mombaerts P (2002) Multiple new and isolated families within the mouse superfamily of V1r vomeronasal receptors. Nat Neurosci 5:134-140.

Ryba NJ, Tirindelli R (1997) A new multigene family of putative pheromone receptors. Neuron 19:371-379.

Sahay A, Molliver ME, Ginty DD, Kolodkin AL (2003) Semaphorin 3F is critical for development of limbic system circuitry and is required in neurons for selective CNS axon guidance events. J Neurosci 23:6671-6680.

Schwarting GA, Kostek C, Ahmad N, Dibble C, Pays L, Puschel AW (2000) Semaphorin $3 \mathrm{~A}$ is required for guidance of olfactory axons in mice. J Neurosci 20:7691-7697.

Schwarting GA, Raitcheva D, Crandall JE, Burkhardt C, Puschel AW (2004) Semaphorin 3A-mediated axon guidance regulates convergence and targeting of P2 odorant receptor axons. Eur J Neurosci 19:1800-1810.
Seibt J, Schuurmans C, Gradwhol G, Dehay C, Vanderhaeghen P, Guillemot F, Polleux F (2003) Neurogenin2 specifies the connectivity of thalamic neurons by controlling axon responsiveness to intermediate target cues. Neuron 39:439-452.

Tanaka M, Treloar H, Kalb RG, Greer CA, Strittmatter SM (1999) G(o) protein-dependent survival of primary accessory olfactory neurons. Proc Natl Acad Sci USA 96:14106-14111.

Taniguchi M, Nagao H, Takahashi YK, Yamaguchi M, Mitsui S, Yagi T, Mori K, Shimizu T (2003) Distorted odor maps in the olfactory bulb of semaphorin 3A-deficient mice. J Neurosci 23:1390-1397.

Tenne-Brown J, Key B (1999) Errors in lamina growth of primary olfactory axons in the rat and mouse olfactory bulb. J Comp Neurol 410:20-30.

Walz A, Rodriguez I, Mombaerts P (2002) Aberrant sensory innervation of the olfactory bulb in neuropilin-2 mutant mice. J Neurosci 22:4025-4035.

Yang XW, Model P, Heintz N (1997) Homologous recombination based modification in Escherichia coli and germline transmission in transgenic mice of a bacterial artificial chromosome. Nat Biotechnol 15:859-865.

Zhu Y, Romero MI, Ghosh P, Ye Z, Charnay P, Rushing EJ, Marth JD, Parada LF (2001) Ablation of NF1 function in neurons induces abnormal development of cerebral cortex and reactive gliosis in the brain. Genes Dev $15: 859-876$. 